MSOC.JR.06 JOURNAL OF SYNCHROTRON RADIATION (JSR). J.R.Helliwell, S.S.Hasnain, and H.Kamitsubo, Dept. Of Chemistry, University of Manchester, Manchester, M13 9PLU.K.

JSR was launched in late 1994 with an Inaugural Issue, ran 6 regular issues through 1995 and has now entered its 3 rd volume in 1996. The papers published have covered all regions of the synchrotron radiation spectrum and in particular embrace sources, instrumentation and methods, fully in the spirit of the objectives of the new journal, namely to provide a focus for the whole of the synchrotron radiation community. The interfaces between the other IUCr journals, especially JAC, has been effectively realised through cross-editorial board appointments. We now have to realise economic viability and to increase the number of pages per issue, which is running lower than estimated (eg for 1995328 pages were published in the 6 issues). Monitoring also of the journal impact factors (citation rate per paper) will be necessary as libraries seek a wider range of objective methods for determining subscription choices. Finally via membership within the Electronic Publishing Committee of the IUCr we are monitoring new technical developments carefully.

MSOC.JR.07 CHESTER PUBLISHING OPERATIONS. P.R. Strickland and B. McMahon, International Union of Crystallography, 5 Abbey Square, Chester CH1 2HU, England

In recent years there have been major changes in the operations of scientific publishers. The Editorial Office in Chester, whose principal function is the production of the journals Acta Crystallographica, Joumal of Applied Crystallography and Journal of Synchrotron Radiation, has kept abreast of these changes and is well positioned to provide new electronic services.

The number of machine-readable submissions to the Union's journals has continued to increase markedly. The entire production of Acta Crystallographica Section C is now undertaken from machine-readable submissions in CIF format. This has proved to be an efficient method for producing Section $C$, and the techniques learned will be useful in the future development of other $\mathrm{IUCr}$ journals and publications.

Several electronic services related to the publishing of the journals are now provided by the Editorial Office. These include a full online contents service on the World Wide Web, manuscript status information, author indexes, and printcif and checkcif services for authors submitting CIF files. The web presence of the Union is expected to increase and the use of new media, such as CD-ROMs, is under consideration. This effort has been backed by increased spending on $R \& D$.

Another development since the last congress of the IUCr, is the launch, in 1994, of the Joumal of Synchrotron Radiation. The journal aims to cover all regions of the synchrotron radiation spectrum and to promote the rapid exchange of information across the whole synchrotron radiation community. Acta Crystallographica Section D, first published in 1993, has been well received and has published a number of special issues on Direct Methods, Crystallization and Drug Design.

A number of other publications are produced by the Chester Office. The International Tables for Ciystallography and the World Directory of Crystallography are the most important of these. The World Directory is also accessible online.

\section{International Tables}

OC.IT.01 STATUS OF VOLUME A: SPACE-GROUP SYMMETRY Th. Hahn, Institut fuer Kristallographie, RheinischWestfaelische Technische Hochschule, D-52056 Aachen, Germany,

The Fourth, revised Edition of Volume A of International Tables for Crystallography was published in the spring of 1995. A corrected reprint of this edition is presently in the press. Two new features are noteworthly for the fourth edition:

(i) Completion of the space-group-diagram project: all 17 plane groups and 230 space groups now contain new diagrams; also the explanatory diagrams in Section 2.6 were newly done. Special attention is drawn to some new features of the cubic diagrams for which examples will be given.

(ii) In accordance with a recent Nomenclature Report of the IUCr [de Wolff et al., Acta Cryst. (1992). A 48, 727-732] the new graphical symbol ..-.. - for "double" glide planes $e$ oriented "normal" and "inclined" to the plane of projection has been incorporated in 17 centred orthorhombic, tetragonal, and cubic space-groups. The introduction of the glide plane $e$ leads to new symbols for the following five space-groups:

$\begin{array}{llcccc}\text { Space-group No. } & 39 & 41 & 64 & 67 & 68 \\ \text { Present symbol } & \text { Abm2 } & \text { Aba2 } & \text { Cmca } & \text { Cmma } & \text { Ccca } \\ \text { New symbol } & \text { Aem2 } & \text { Aea2 } & \text { Cmce } & \text { Cmme } & \text { Ccce. }\end{array}$ New symbol Aem2 Aeaz Cimce Chme

The implications of these new symbols will be explained.

OC.IT.02 STATUS OF VOLUME B: RECIPROCAL SPACE. Uri Shmueli, School of Chemistry, Tel Aviv University, 69978 Tel Aviv, Israel

The first edition of Volume $B$ of Intemational Tables for Crystallography was published in 1993, and work on the preparation of the second edition was soon commenced. The plans for the second edition included (i) minor revisions and corrections, (ii) major revisions of several existing chapters in order to extend their scope and/or update them with recent developments, and (iii) invitations of contributions on several relevant topics not treated in the first edition.

Most of the minor changes that did not require repagination were taken care of by the recent corrected second printing of Volume $B$, which will ensure its availability until the second edition is ready.

At the time of writing this Abstract most of the planned minor and major revisions of existing chapters have been received by the Editor and are being prepared for inclusion in the second edition of the volume. Their summary will be presented at the Open Meeting of the Commission on International Tables.

New contributions on the following topics were invited for the second edition of Volume $B$ :

1. Space-group representations in reciprocal space.

2. Direct methods in electron crystallography.

3. Diffraction by polymers.

4. Reciprocal-space images of aperiodic crystals.

5. Dynamical theory of neutron diffraction.

At the time of writing this Abstract, advanced drafts of three contributions on the above topics have been received. Further developments are expected and will be reported at the Open Meeting. 